\title{
A systematic review and meta-analysis of Harmonic technology compared with conventional techniques in mastectomy and breast-conserving surgery with lymphadenectomy for breast cancer
}

This article was published in the following Dove Press journal:

Breast Cancer - Targets and Therapy

18 July 2016

Number of times this article has been viewed

\section{Hang Cheng' \\ Jeffrey W Clymer' \\ Nicole C Ferko² \\ Leena Patel ${ }^{2}$ \\ Ireena M Soleas ${ }^{2}$ \\ Chris G Cameron ${ }^{2}$ \\ Piet Hinoul'}

'Ethicon Inc., Cincinnati, OH, USA;

${ }^{2}$ Cornerstone Research Group,

Burlington, ON, Canada
Correspondence: Jeffrey W Clymer Ethicon Inc., 4545 Creek Road,

Cincinnati, OH 45242, USA

$\mathrm{Tel}+\mathrm{I} 5133373318$

Email jclymer@its.jnj.com
Background: Mastectomy and breast-conserving surgery (BCS) are important treatment options for breast cancer patients. A previous meta-analysis demonstrated that the risk of certain complications can be reduced with the Harmonic technology compared with conventional methods in mastectomy. However, the meta-analysis did not include studies of BCS patients and focused on a subset of surgical complications. The objective of this study was to compare Harmonic technology and conventional techniques for a range of clinical outcomes and complications in both mastectomy and BCS patients, including axillary lymph node dissection.

Methods: A comprehensive literature search was performed for randomized controlled trials comparing Harmonic technology and conventional methods in breast cancer surgery. Outcome measures included blood loss, drainage volume, total complications, seroma, necrosis, wound infections, ecchymosis, hematoma, hospital length of stay, and operating time. Risk of bias was analyzed for all studies. Meta-analysis was performed using random-effects models for mean differences of continuous variables and a fixed-effects model for risk ratios of dichotomous variables.

Results: Twelve studies met the inclusion criteria. Across surgery types, compared to conventional techniques, Harmonic technology reduced total complications by $52 \%(P=0.002)$, seroma by $46 \%(P<0.0001)$, necrosis by $49 \%(P=0.04)$, postoperative chest wall drainage by $46 \%(P=0.0005)$, blood loss by $38 \%(P=0.0005)$, and length of stay by $22 \%(P=0.007)$. Although benefits generally appeared greatest in mastectomy patients with lymph node dissection, Harmonic technology showed significant reductions in complications in the BCS study subgroup.

Conclusion: In this meta-analysis of both mastectomy and BCS procedures, the use of Harmonic technology reduced the risk of most complications by about half across breast cancer surgery patients. These benefits may be due to superior hemostatic capabilities of Harmonic technology and better dissection, particularly lymph node dissection. Reduction in complications and other resource outcomes may engender lower downstream health care costs.

Keywords: dissection, complications, ultrasonic

\section{Introduction}

Breast cancer is the leading cause of cancer-related deaths among females worldwide, with an incidence rate of close to 90 cases per 100,000 females. The occurrence of 
breast cancer, especially in low- to middle-income countries, continues to increase with time. ${ }^{1}$ The surgical treatment of breast cancer has undergone substantial changes over the last few decades. Mastectomy remains an important surgical option for breast cancer patients; however, for patients with earlier stages of breast cancer, breast-conserving surgery (BCS) followed by radiation therapy is a safe alternative to radical mastectomy, with acceptable local recurrence rates, similar survival, and improved cosmetic outcomes. ${ }^{2}$ Both mastectomy and BCS often involve axillary lymph node dissection as the axillary lymph nodes are a common site of metastasis in breast carcinoma, and axillary node status provides an important prognostic indicator through histological examination. ${ }^{3-8}$

Surgical complications can be common with breast cancer surgeries, particularly with modified radical mastectomies. Apart from the long-term risk of lymphedema in postoperative breast surgery patients, several acute surgical complications may occur such as hemorrhage, ${ }^{9}$ tissue necrosis, ${ }^{10}$ wound infection, ${ }^{11}$ and seroma. ${ }^{12}$ Seromas represent the most frequent complication of mastectomy, developing in close to $30 \%$ of patients. ${ }^{12}$ Sealing the lymphatic ducts is thought to be particularly important in reducing the risk of postoperative seromas. ${ }^{7}$ Breast surgery complications may be reduced through the use of meticulous techniques, hemostasis, and wound closure. ${ }^{13,14}$

Monopolar or bipolar electrosurgery is a common conventional method used to dissect tissue and control blood loss in breast cancer surgery, along with other conventional methods such as ligation, scalpel, and scissors often being used in BCS. ${ }^{15}$ Despite the benefits of electrosurgery in controlling blood loss, studies have indicated that risk of complications, such as seroma, may be increased with this technique. ${ }^{16}$ In particular, electrosurgery can cause thermal injury and incomplete sealing of the vessels and lymphatic channels, leading to surgical complications. ${ }^{17}$

Harmonic devices (Harmonic ${ }^{\circledR}$; Ethicon Inc., Cincinnati, $\mathrm{OH}$, USA) perform simultaneous ultrasonic cutting and coagulation through the use of mechanical vibration, producing hemostasis at a lower temperature than electrosurgical devices while providing excellent dissecting capability. ${ }^{18,19}$ Several systematic reviews and meta-analyses have reported favorable outcomes with the Harmonic technology compared to conventional methods across several types of surgeries. ${ }^{20-23}$ A recent meta-analysis by Huang et $a l,{ }^{23}$ in modified radical mastectomy for breast cancer, reported that Harmonic technology was associated with a significant reduction in postoperative drainage, seroma development, intraoperative blood loss, and wound complications compared with electrosurgery dissection. However, it is noted that studies of BCS patients were not included in the meta-analysis, and only a subset of surgical complications was evaluated.

The purpose of this systematic review and meta-analysis was to evaluate both efficacy and complications associated with Harmonic technology versus conventional techniques in both mastectomy and BCS patients, typically involving lymph node dissection, using all the latest randomized controlled trials (RCTs) available.

\section{Methods}

MEDLINE via PubMed, Scopus, and the Cochrane Central Register of Controlled Trials (CENTRAL) were systematically searched for all indexed articles published between January 1, 1998, and May 23, 2014. The search strategy combined different terms applied to Harmonic devices [Title or Abstract] with comparative study, controlled clinical trial or randomized trial [Publication Type], and Humans [MeSH] (Supplementary material). A search ranging from November 23, 2013, through May 23, 2014, identical to that detailed earlier, without human or publication type limits, was also conducted in PubMed to capture publisher-supplied citations not yet indexed in MEDLINE. In addition, a manual search of reference lists from accepted studies and recent reviews was performed to supplement the electronic search. No language restrictions were applied in this systematic review, and meeting abstracts were not searched.

The PICOS categories (ie, population, intervention, comparator, outcomes, and study design) were used to describe specific inclusion criteria. Studies were deemed eligible for inclusion if they were RCTs comparing the use of Harmonic surgical technology to conventional methods, such as traditional scalpel, ligation, and electrosurgery (Table 1), in human subjects for mastectomy or BCS with lymph node dissection procedures. Full-text articles were then excluded if they were not an RCT. The eligibility of each publication was evaluated by two independent reviewers, and a third reviewer was consulted in the case of disagreements regarding study inclusion.

Study details (ie, baseline characteristics and outcomes) of included publications were extracted using a data extraction form. Data were extracted by a single reviewer and subsequently cross-checked for accuracy, consistency, and completeness by a second reviewer. Discrepancies were resolved through consensus. The following data elements were extracted onto a standardized data collection sheet: type of surgical procedure, key patient characteristics, region, 
Table I Study and baseline characteristics for studies meeting inclusion criteria

\begin{tabular}{|c|c|c|c|c|c|c|}
\hline Reference & Country & $\begin{array}{l}\text { Interventions } \\
\text { evaluated }\end{array}$ & $\mathbf{n}$ & $\begin{array}{l}\text { Mean age } \pm \\
\text { SD or (range) }\end{array}$ & Surgery & Included end points \\
\hline Anlar et $\mathrm{al}^{5}$ & Turkey & $\begin{array}{l}\text { UltraCision } \\
\text { Harmonic } \\
\text { scalpel } \\
\text { Electrocautery } \\
\text { Scalpel }\end{array}$ & $\begin{array}{l}41 \\
40\end{array}$ & $\begin{array}{l}52(24-82)^{\mathrm{a}} \\
51(29-68)^{\mathrm{a}}\end{array}$ & $\begin{array}{l}\text { Modified radical } \\
\text { mastectomy and axillary } \\
\text { LN dissection }\end{array}$ & $\begin{array}{l}\text { - Operating time } \\
\text { - Intraoperative blood loss } \\
\text { - Overall seroma } \\
\text { - Hematoma } \\
\text { - Wound infection } \\
\text { - Necrosis } \\
\text { - Ecchymosis }\end{array}$ \\
\hline Bohm et $\mathrm{al}^{4}$ & Germany & $\begin{array}{l}\text { Harmonic } \\
\text { FOCUS + } \\
\text { electrocautery } \\
\text { Scalpel and } \\
\text { electrocautery } \\
\text { with scissors }\end{array}$ & 52 & $59.1 \pm 12.3$ & $\begin{array}{l}\text { BCS (lumpectomy and } \\
\text { segmentectomy) and } \\
\text { axillary dissection (when } \\
\text { indicated) }\end{array}$ & $\begin{array}{l}\text { - Operating time } \\
\text { - Postoperative drainage volume of chest wall } \\
\text { - Postoperative hospital length of stay } \\
\text { - Overall seroma } \\
\text { - Hematoma }\end{array}$ \\
\hline $\begin{array}{l}\text { Damani } \\
\text { et } \mathrm{al}^{32}\end{array}$ & Pakistan & $\begin{array}{l}\text { Ultracision } \\
\text { Harmonic } \\
\text { scalpel } \\
\text { Olympus } \\
\text { electrocautery } \\
\text { (monopolar } \\
\text { diathermy) }\end{array}$ & 25 & $43.9 \pm 7.1$ & $\begin{array}{l}\text { Modified radical } \\
\text { mastectomy }\end{array}$ & $\begin{array}{l}\text { - Operating time } \\
\text { - Intraoperative blood loss } \\
\text { - Postoperative drainage volume of chest wall } \\
\text { - Overall seroma } \\
\text { - Hematoma } \\
\text { - Wound infection } \\
\text { - Necrosis }\end{array}$ \\
\hline $\mathrm{He}$ et $\mathrm{al}^{6}$ & $\begin{array}{l}\text { People's } \\
\text { Republic of } \\
\text { China }\end{array}$ & $\begin{array}{l}\text { Harmonic } \\
\text { FOCUS } \\
\text { Electrocautery }\end{array}$ & 64 & $48.5(23-72)^{a}$ & $\begin{array}{l}\text { Axillary LN dissection } \\
\text { for breast cancer with } \\
\text { mastectomy or BC } \\
\text { (lumpectomy) surgery }\end{array}$ & $\begin{array}{l}\text { - Operating time } \\
\text { - Intraoperative blood loss } \\
\text { - Postoperative hospital length of stay } \\
\text { - Overall seroma } \\
\text { - Hematoma } \\
\text { - Wound infection } \\
\text { - Necrosis }\end{array}$ \\
\hline lovino et $\mathrm{al}^{7}$ & Italy & $\begin{array}{l}\text { Harmonic } \\
\text { scalpel } \\
\text { Traditional } \\
\text { scalpel, scissors, } \\
\text { ligations, } \\
\text { electrocautery }\end{array}$ & 30 & $\begin{array}{l}6 I(39-8 I)^{\mathrm{a}} \\
65(42-78)^{\mathrm{a}}\end{array}$ & $\begin{array}{l}\text { Axillary LN dissection } \\
\text { for breast cancer: } \\
\text { conservative surgery } \\
(83 \%) \text { and mastectomy } \\
(17 \%)\end{array}$ & $\begin{array}{l}\text { - Operating time } \\
\text { - Intraoperative blood loss } \\
\text { - Postoperative drainage volume of chest wall } \\
\text { - Postoperative hospital length of stay } \\
\text { - Overall seroma } \\
\text { - Hematoma } \\
\text { - Wound Infection }\end{array}$ \\
\hline Khan et $\mathrm{al}^{30}$ & Pakistan & $\begin{array}{l}\text { J-Hook } \\
\text { Harmonic } \\
\text { scalpel } \\
\text { Electrocautery }\end{array}$ & 75 & $\begin{array}{l}50 \pm 12.2 \\
48.5 \pm 14.5\end{array}$ & $\begin{array}{l}\text { Modified radical } \\
\text { mastectomy and axillary } \\
\text { LN dissection }\end{array}$ & $\begin{array}{l}\text { - Operating time } \\
\text { - Intraoperative blood loss } \\
\text { - Total complications } \\
\text { - Overall seroma } \\
\text { - Hematoma } \\
\text { - Wound infection } \\
\text { - Necrosis }\end{array}$ \\
\hline Khater $^{31}$ & Egypt & $\begin{array}{l}\text { Harmonic } \\
\text { UltraCision } \\
\text { shears } \\
\text { Valley Lab } \\
\text { Force FX } \\
\text { Electrocautery }\end{array}$ & 30 & $56.27 \pm 9.05$ & $\begin{array}{l}\text { Modified radical } \\
\text { mastectomy and axilia } \\
\text { dissection }\end{array}$ & $\begin{array}{l}\text { - Operating time } \\
\text { - Intraoperative blood loss } \\
\text { - Overall seroma } \\
\text { - Hematoma } \\
\text { - Necrosis }\end{array}$ \\
\hline $\begin{array}{l}\text { Kontos } \\
\text { et } \mathrm{al}^{26}\end{array}$ & England & $\begin{array}{l}\text { UltraCision } \\
\text { Harmonic } \\
\text { scalpel with } \\
\text { curved blade or } \\
\text { hook } \\
\text { Valley Lab } \\
\text { Force FX } \\
\text { Electrocautery }\end{array}$ & 15 & $58(32-86)^{\mathrm{b}}$ & $\begin{array}{l}\text { Modified radical } \\
\text { mastectomy with } \\
\text { sentinel node biopsy, } \\
\text { skin sparing mastectomy } \\
\text { with immediate } \\
\text { reconstruction and wide } \\
\text { excision and axillary } \\
\text { clearance as part of BCS }\end{array}$ & $\begin{array}{l}\text { - Operating time } \\
\text { - Total complications } \\
\text { - Overall seroma } \\
\text { - Hematoma } \\
\text { - Wound infection } \\
\text { - Necrosis }\end{array}$ \\
\hline
\end{tabular}


Table I (Continued)

\begin{tabular}{|c|c|c|c|c|c|c|}
\hline Reference & Country & $\begin{array}{l}\text { Interventions } \\
\text { evaluated }\end{array}$ & $\mathbf{n}$ & $\begin{array}{l}\text { Mean age } \pm \\
\text { SD or (range) }\end{array}$ & Surgery & Included end points \\
\hline $\begin{array}{l}\text { Kozomara } \\
\text { et } \mathrm{al}^{33}\end{array}$ & $\begin{array}{l}\text { Bosnia and } \\
\text { Herzegovina }\end{array}$ & $\begin{array}{l}\text { UltraCision } \\
\text { Harmonic } \\
\text { scalpel } \\
\text { Olympus } \\
\text { electrocautery } \\
\text { (monopolar) }\end{array}$ & 30 & $62 \pm 17$ & $\begin{array}{l}\text { Modified radical } \\
\text { mastectomy and LN } \\
\text { dissection }\end{array}$ & $\begin{array}{l}\text { - Operating time } \\
\text { - Intraoperative blood loss } \\
\text { - Overall Seroma } \\
\text { - Wound infection }\end{array}$ \\
\hline $\begin{array}{l}\text { Lumachi } \\
\text { et } \mathrm{al}^{28}\end{array}$ & Italy & $\begin{array}{l}\text { UltraCision } \\
\text { Harmonic } \\
\text { scalpel } \\
\text { Scalpel }\end{array}$ & 38 & $55.1 \pm I I .8$ & $\begin{array}{l}\text { Modified radical } \\
\text { mastectomy or BC } \\
\text { (lumpectomy) surgery } \\
\text { with axillary LN } \\
\text { dissection for breast } \\
\text { cancer; no immediate } \\
\text { breast reconstruction }\end{array}$ & - Postoperative hospital length of stay \\
\hline $\begin{array}{l}\text { Rohaizak } \\
\text { et } \mathrm{al}^{8}\end{array}$ & Malaysia & $\begin{array}{l}\text { UltraCision } \\
\text { Harmonic } \\
\text { scalpel } \\
\text { Value Lab } \\
\text { Diathermy } \\
\text { Electrocautery }\end{array}$ & $\begin{array}{l}20 \\
20\end{array}$ & $\begin{array}{l}53.0 \pm 7.0 \\
53.0 \pm 9.0\end{array}$ & $\begin{array}{l}\text { Modified radical } \\
\text { mastectomy and axillary } \\
\text { LN dissection }\end{array}$ & $\begin{array}{l}\text { - Postoperative drainage volume of chest wall } \\
\text { - Overall seroma } \\
\text { - Wound infection } \\
\text { - Necrosis }\end{array}$ \\
\hline $\begin{array}{l}\text { Yilmaz } \\
\text { et } \mathrm{al}^{29}\end{array}$ & Turkey & $\begin{array}{l}\text { UltraCision } \\
\text { Harmonic } \\
\text { scalpel } \\
\text { Scalpel } \\
\text { Olympus } \\
\text { EUS } 10 \\
\text { Electrocautery }\end{array}$ & $\begin{array}{l}29 \\
27 \\
26\end{array}$ & $\begin{array}{l}52.0 \pm 9.5 \\
50.2 \pm 9.3 \\
48.5 \pm 9.8\end{array}$ & $\begin{array}{l}\text { Modified radical } \\
\text { mastectomy and axillary } \\
\text { LN dissection }\end{array}$ & $\begin{array}{l}\text { - Operating time } \\
\text { - Intraoperative blood loss } \\
\text { - Overall seroma } \\
\text { - Hematoma } \\
\text { - Wound infection } \\
\text { - Necrosis } \\
\text { - Ecchymosis }\end{array}$ \\
\hline
\end{tabular}

Notes: ${ }^{a}$ Age reported as median (range). ${ }^{b}$ Age reported as mean (range). ${ }^{\mathrm{C}}$ Only an overall age range was provided by the authors.

Abbreviations: LN, lymph node; SD, standard deviation; BCS, breast-conserving surgery.

study design, devices and/or techniques utilized, number of patients, and included outcomes.

The following clinical outcome measures were included: 1) operating time, 2) intraoperative blood loss, 3) postoperative drainage volume of the chest wall, 4) postoperative hospital length of stay, 5) total complications, 6) overall seroma, 7) hematoma, 8) wound infection, 9) necrosis, and 10) ecchymosis. The seroma outcome pooled studies reporting overall rates of seroma, as well as studies reporting seroma results specific to the chest and/or axillary regions only. The mean and standard deviation (SD) variance measure was not reported in two studies ${ }^{5,7}$ for the operating time and intraoperative blood loss outcomes. Study authors were not contacted to retrieve missing data; however, standard methods provided by Cochrane $^{24}$ and methods outlined by Hozo et $\mathrm{al}^{25}$ were used to impute missing data. Additionally, the SD was not provided in one study ${ }^{26}$ for operating time; thus, the reported $P$-value was used to impute this variance measure. Similarly, one study ${ }^{4}$ did not report the SD variance measure for the postoperative drainage volume from the chest wall outcome, and the $P$-value was used to impute this missing variance measure. This same study $^{4}$ did not report the mean and SD variance measure for the postoperative hospital length of stay outcome. Methods provided by Cochrane ${ }^{24}$ and outlined by Hozo et al ${ }^{25}$ were used to impute these missing data. Due to missing variance measures, the mean number of lymph nodes dissected was not included as an outcome in this analysis.

The quality of the included studies was assessed using the risk of bias algorithm outlined by the Cochrane guidelines. ${ }^{24}$ Based on seven prespecified domains (sequence generation, allocation concealment, blinding of participants and personnel, blinding of outcome assessment, incomplete outcome data, selective outcome reporting, and other sources of bias), publications were scored as having low, unclear, or high risk of bias. Final decisions were based on the combination of these factors and individual characteristics of each study. Two authors independently assessed the quality of the study. Differences were resolved through discussion with a third author.

The primary meta-analysis was performed using Review Manager (Version 5.3; The Nordic Cochrane Centre, The Cochrane Collaboration, Copenhagen, Denmark, 2014). Mean differences (MDs) for continuous outcomes (operating time, intraoperative blood loss, postoperative drainage volume of the chest wall, and postoperative hospital length of 
stay) were calculated using the inverse variance method. The meta-analysis of continuous outcomes used a random-effects model, due to the presence of some study heterogeneity. Risk ratios (RRs) for dichotomous outcomes (total complications, overall seroma, hematoma, wound infection, necrosis, and ecchymosis) were calculated using the Mantel-Haenszel method. A fixed-effects model was used for the meta-analysis of dichotomous outcomes, as several outcome events were rare and displayed low heterogeneity. Forest plots were generated for all outcomes within Review Manager. Heterogeneity of the included studies was assessed using the $\chi^{2}$ test and $I^{2}$ measure.
The primary analysis compared Harmonic technology to conventional techniques and presented results for four different subgroups of studies, depending on whether studies only included mastectomy, only included BCS, included both mastectomy and BCS, and whether lymph node dissection was performed. A secondary analysis was conducted for dichotomous outcomes, where the odds ratios (ORs) were calculated using the Mantel-Haenszel method. Dichotomous outcomes that were considered rare events (ie, with event rates $<1 \%$ : hematoma, wound infection, necrosis) were analyzed using the Peto one-step OR method with a fixed-effects model. ${ }^{27}$

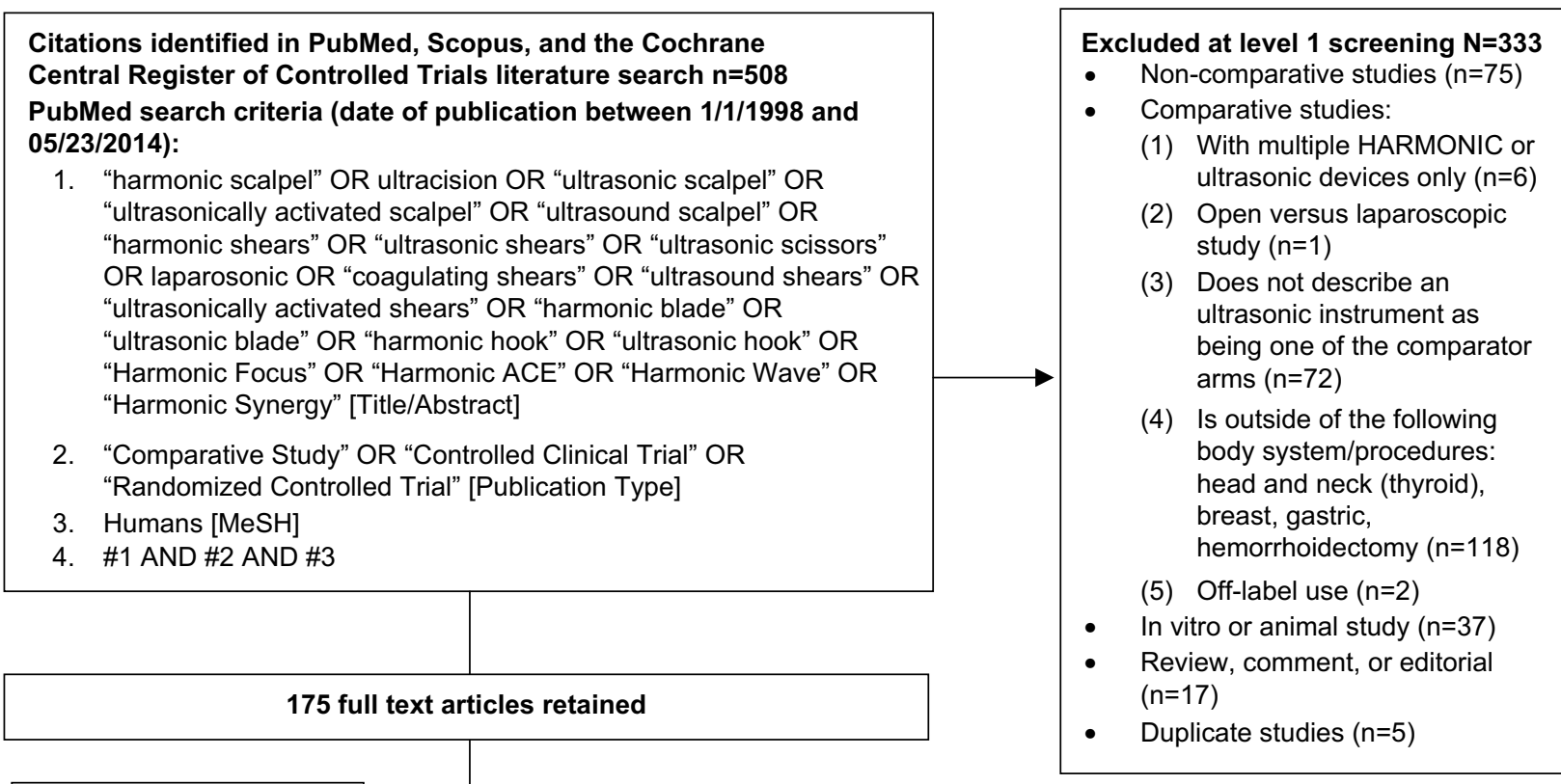

\section{6 additional full text} articles identified from manual review of citations

\section{Excluded at level 2 screening $\mathrm{N}=189$}

- No explicit description of HARMONIC device $(n=23)$

- Conference abstract only ( $n=16)$

- Does not provide economic or clinical patient outcomes at the patient or summary level required for extraction $(n=9)$

- No ultrasonic comparator group $(n=1)$

- Off-label use (n=2)

- Full text article unavailable $(n=2)$

- Kin studies $(n=3)$

- Review $(n=1)$

- Published before $2000(n=3)$

- Not a mastectomy or BCS + LN dissection procedure $(n=122)$

- Not an RCT=(n=7)

\section{2 studies included in meta-analysis}

Figure I PRISMA diagram for the systematic literature review.

Abbreviations: BCS, breast-conserving surgery; LN, lymph node; RCT, randomized controlled trial. 
Sensitivity analyses were completed for device-use randomization in included studies, where studies not randomizing device use in breast surgery were excluded ${ }^{28}$ or studies not randomizing device use in lymph node dissection were excluded.,29 Further, sensitivity analyses were conducted by excluding any studies from outcomes for which imputed data were required or excluding studies deemed to have a high risk of bias. Forest plots are provided in the main text for results that are statistically significant and when four or more studies informed the analysis.

\section{Results}

The systematic search resulted in the identification of 508 citations, and 26 additional studies were identified through manual searches of accepted studies and published systematic reviews. Of the 508 citations identified in the search, 333 were further excluded following abstract screening (Figure 1). Of the 199 full-text articles retrieved and reviewed, 189 were further excluded primarily if studies were non-RCTs, there was no explicit description of a Harmonic branded device, the surgical procedure was not breast surgery or lymph node dissection, and only conference abstracts were available. Overall, 12 studies consisting of 890 patients in total reporting on Harmonic technology use in breast surgery and lymph node dissection procedures were included in the meta-analysis. ${ }^{48,26,28-33}$

Study characteristics are summarized in Table 1. Sample sizes of the included studies ranged from 32 to 150 patients, and in all studies, Harmonic technology was compared to conventional techniques in breast surgery. Different Harmonic device technologies were used in these analyses. The UltraCision Harmonic scalpel $1^{5,8,26,28,29,32,33}$ or Harmonic scalpel ${ }^{7,30}$ were used in nine studies, while the Harmonic FOCUS ${ }^{\circledR}$ device was used in two studies. ${ }^{4,6}$ The Harmonic UltraCision shears were used in one study. ${ }^{31}$ Overall, seven studies ${ }^{6,8,26,30-33}$ compared Harmonic technology to electrosurgery. One study $^{7}$ compared Harmonic technology to standard scalpel blade and electrosurgery with scissors and ligations, and one

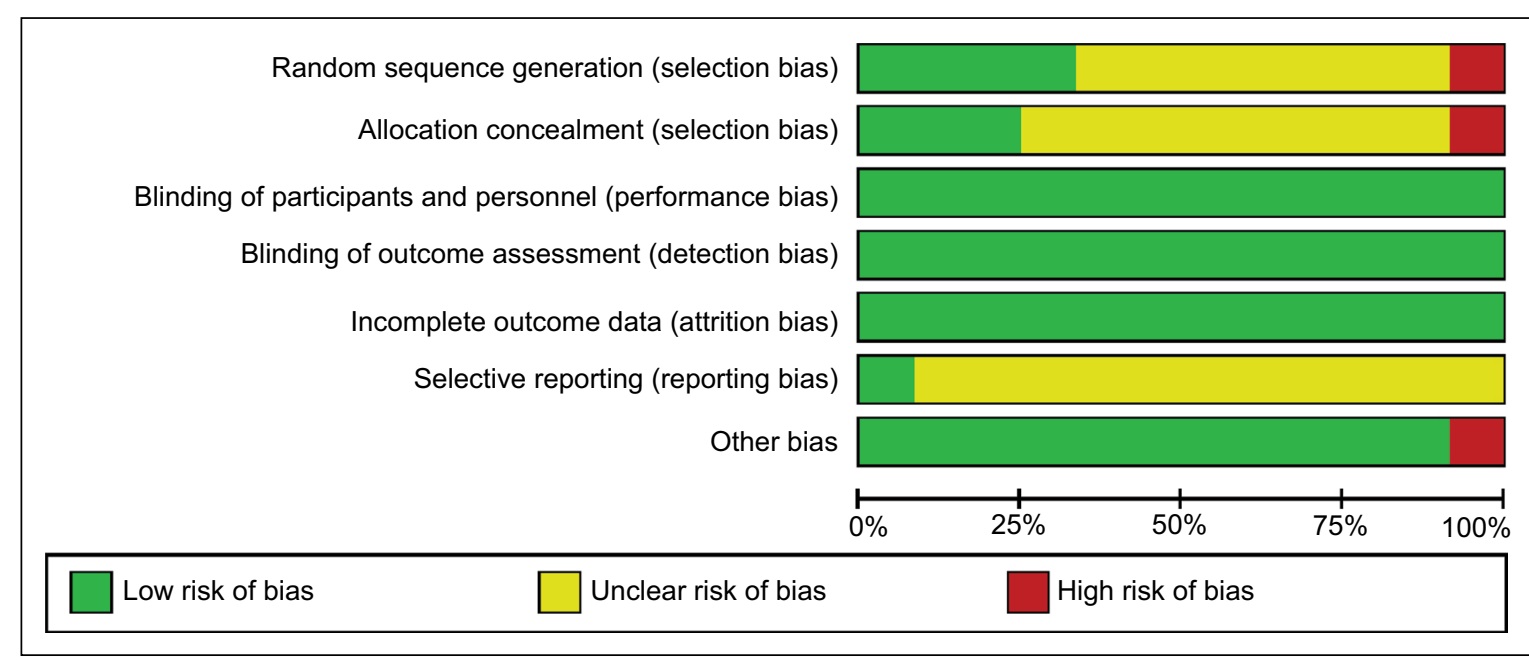

Figure 2 Risk of bias assessment for studies meeting inclusion criteria.

Table 2 Qualitative risk of bias assessment summary

\begin{tabular}{|c|c|c|c|c|c|c|c|}
\hline Study & $\begin{array}{l}\text { Sequence } \\
\text { generation }\end{array}$ & $\begin{array}{l}\text { Allocation } \\
\text { concealment }\end{array}$ & $\begin{array}{l}\text { Blinding of personnel } \\
\text { and participants }\end{array}$ & $\begin{array}{l}\text { Blinding of } \\
\text { outcomes }\end{array}$ & $\begin{array}{l}\text { Incomplete outcome } \\
\text { data addressed }\end{array}$ & $\begin{array}{l}\text { Free of selective } \\
\text { reporting }\end{array}$ & $\begin{array}{l}\text { Free of } \\
\text { other bias }\end{array}$ \\
\hline Anlar et $\mathrm{al}^{5}$ & Unclear & Unclear & Yes & Yes & Yes & Unclear & Yes \\
\hline Bohm et $\mathrm{al}^{4}$ & Yes & Unclear & Yes & Yes & Yes & Unclear & Yes \\
\hline Damani et $\mathrm{al}^{32}$ & Unclear & Unclear & Yes & Yes & Yes & Unclear & Yes \\
\hline He et $\mathrm{al}^{6}$ & Unclear & Yes & Yes & Yes & Yes & Unclear & Yes \\
\hline lovino et $\mathrm{al}^{7}$ & Yes & Yes & Yes & Yes & Yes & Unclear & Yes \\
\hline Khan et $\mathrm{al}^{30}$ & Yes & Unclear & Yes & Yes & Yes & Yes & No \\
\hline Khater ${ }^{31}$ & Unclear & Unclear & Yes & Yes & Yes & Unclear & Yes \\
\hline Kontos et $\mathrm{al}^{26}$ & Yes & Yes & Yes & Yes & Yes & Unclear & Yes \\
\hline Kozomara et $\mathrm{al}^{33}$ & Unclear & Unclear & Yes & Yes & Yes & Unclear & Yes \\
\hline Lumachi et $\mathrm{al}^{28}$ & Unclear & Unclear & Yes & Yes & Yes & Unclear & Yes \\
\hline Rohaizak et $\mathrm{al}^{8}$ & No & No & Yes & Yes & Yes & Unclear & Yes \\
\hline Yilmaz et $\mathrm{al}^{29}$ & Unclear & Unclear & Yes & Yes & Yes & Unclear & Yes \\
\hline
\end{tabular}

Notes: Yes, low risk of bias; No, high risk of bias. 
compared Harmonic technology ${ }^{4}$ to standard scalpel blade and electrosurgery with scissors. Harmonic technology was compared to standard scalpel use in one study. ${ }^{28}$ Two threearmed studies ${ }^{5,29}$ were included in this analysis comparing Harmonic technology to electrosurgery or cold steel scalpel use; however, only results from the electrosurgery arm were reported in the conventional group of the current analysis. The mean number of lymph nodes removed was comparable between patients in Harmonic technology and conventional techniques groups, as reported by two of the included studies. ${ }^{6,7}$ One study reported the median number of lymph nodes removed with Harmonic technology as 24 versus 22 lymph nodes, respectively. ${ }^{7}$ The second study reported the mean number of lymph nodes removed as 21 for both Harmonic technology and conventional technique groups. ${ }^{6,7}$

The risk of bias varied across the included studies. Overall results of the risk of bias assessments are reported in Figure 2, and the quality assessment of individual studies is summarized in Table 2. The method of randomization was known in four studies. ${ }^{4,7,26,30}$ One study described randomization through the use of a random number table, ${ }^{4}$ and one described randomization by a computer-generated sequence. ${ }^{30}$ Two studies described randomization through the use of envelopes. ${ }^{7,26}$ One study ${ }^{8}$ was deemed to have a high risk of bias as the randomization sequence was generated through a systematic, nonrandom approach. Three studies ${ }^{6,7,26}$ described concealment of the randomization sequence. Blinding of patients to the surgical technique was reported in two studies, ${ }^{7,30}$ and one study $^{7}$ described blinding of outcome assessors. Outcomes were considered objective and unlikely to be affected by a lack of blinding; thus, risk of performance bias was deemed low in nonblinded studies. There was no missing outcome data in all the included studies. Selective reporting remained unclear in eleven studies, ${ }^{4-8,26,28,29,31-33}$ while one study ${ }^{30}$ was deemed to have a low risk of bias, as it reported no difference in published outcomes compared to the study protocol.

\section{Operating time}

Mean operating time (Harmonic technology: 105.21 minutes, conventional technique: 110.29 minutes) was reduced by 5.07 minutes $(95 \%$ confidence interval [95\% CI]: -10.98 to $0.83 ; P=0.09$; ten studies; $I^{2}=83 \%$ ), although results were not statistically significant (Table 3 ). This translates to a $4.60 \%$ decrease with Harmonic technology compared to conventional methods in breast surgery. For all surgery subgroups, results were not significantly different, with the exception of the mastectomy only (no lymph node dissection) subgroup that reported a significant reduction in operating time with Harmonic technology. ${ }^{32}$

\section{Intraoperative blood loss}

Mean intraoperative blood loss (Harmonic technology: $145.37 \mathrm{~mL}$, conventional technique: $232.90 \mathrm{~mL}$ ) was statistically significantly reduced by $87.54 \mathrm{~mL}(95 \% \mathrm{CI}$ : -137.07 to $-38.02 ; P=0.0005$; eight studies; $I^{2}=99 \%$ ), a $37.59 \%$ decrease with Harmonic technology compared to conventional methods in breast surgery (Figure 3; Table 3). Reductions in intraoperative blood loss were similar across study subgroups, with the greatest reduction reported in studies conducting mastectomies (with lymph node dissection) only.

\section{Postoperative drainage volume of the chest wall}

In contrast to conventional methods in breast surgery, mean postoperative drainage volume of the chest wall (Harmonic technology: $49.96 \mathrm{~mL}$, conventional technique: $92.06 \mathrm{~mL}$ ) was statistically significantly reduced by $42.14 \mathrm{~mL}(95 \%$ CI: -65.90 to $-18.39 ; P=0.0005$; four studies; $I^{2}=87 \%$ ) with the Harmonic scalpel (Figure 4; Table 3). This translates to a $45.77 \%$ decrease with Harmonic technology compared to conventional techniques in breast surgery. Reductions in postoperative drainage volume of the chest wall were statistically significant across all study subgroups, with the greatest reductions observed in studies focusing on mastectomies.

\section{Postoperative hospital length of stay}

Mean postoperative hospital length of stay (Harmonic technology: 4.78 days, conventional techniques: 6.15 days) was statistically significantly reduced by 1.38 days $(95 \%$ CI: -2.38 to $-0.38 ; P=0.007$; four studies; $I^{2}=98 \%$ ) with Harmonic technology, a $22.44 \%$ decrease with Harmonic technology compared to conventional techniques in breast surgery (Figure 5; Table 3). A subgroup analysis for studies including mastectomy (and excluding BCS) was not conducted due to limited data.

\section{Total complications}

Compared to conventional techniques in breast surgery, Harmonic technology resulted in a statistically significant reduction in total complications with an RR of $0.48(95 \%$ CI: $0.30-0.77 ; P=0.002$; two studies; $I^{2}=0 \%$; Table 3 ). This translates to a $52 \%$ decrease with Harmonic technology compared to conventional techniques in breast surgery. For the surgery subgroups, the observed reductions with the Harmonic technology were statistically significant for the study of mastectomy patients and nonstatistically significant for the study including both mastectomy and BCS. 


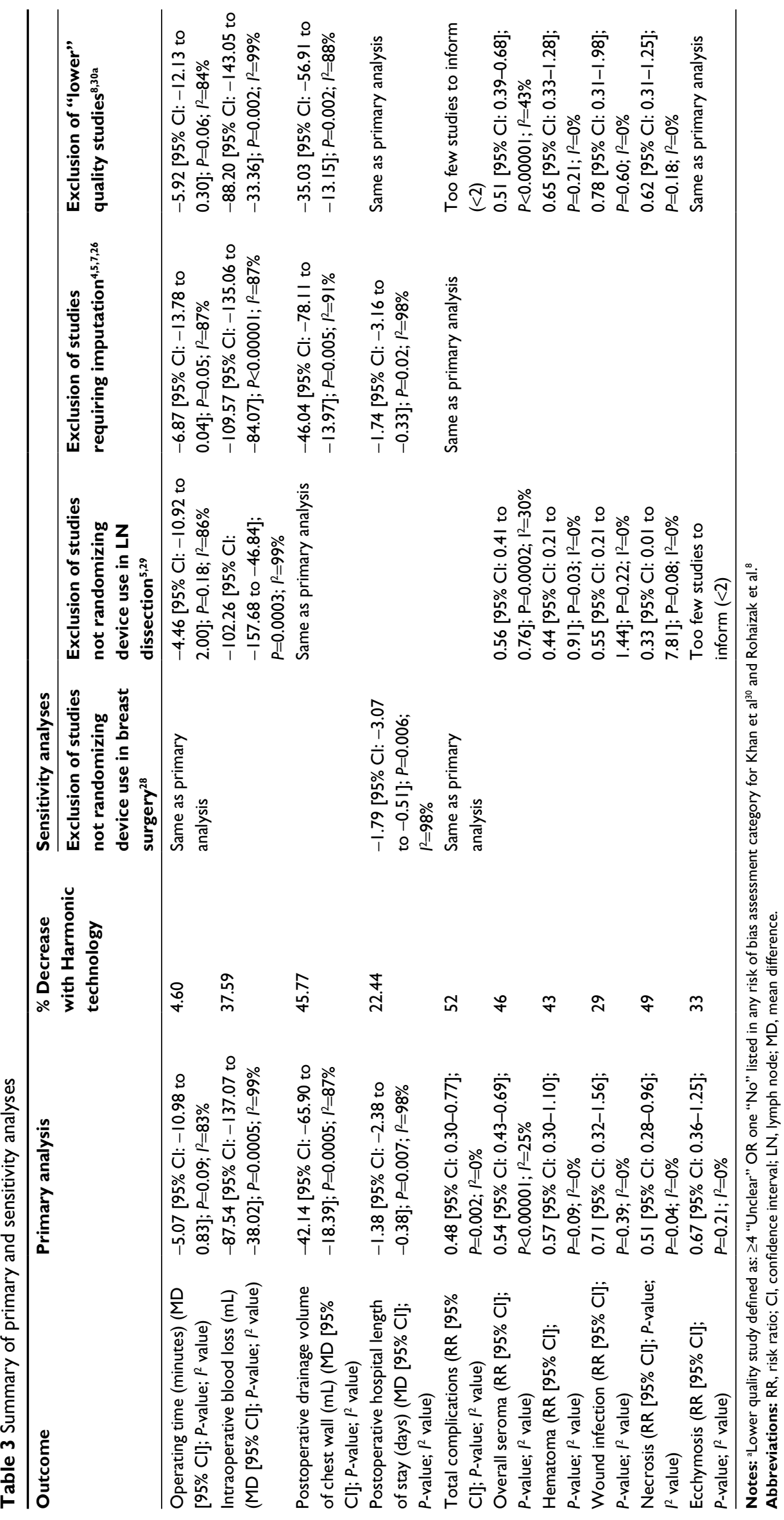




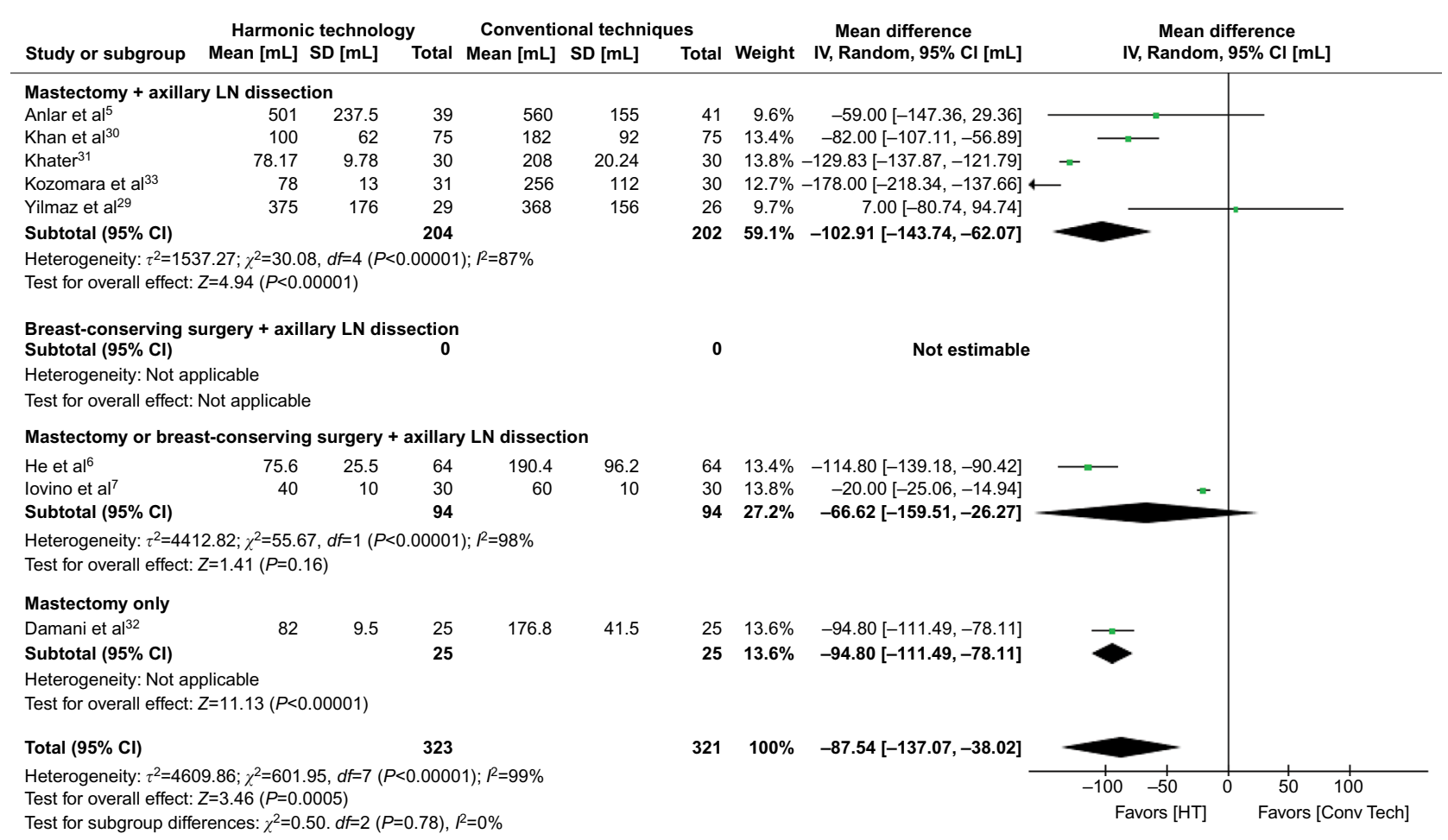

Figure 3 Forest plot of meta-analysis results for intraoperative blood loss $(\mathrm{mL})$.

Abbreviations: SD, standard deviation; Cl, confidence interval; LN, lymph node; HT, Harmonic technology; Conv Tech, conventional techniques; IV, inverse variance.

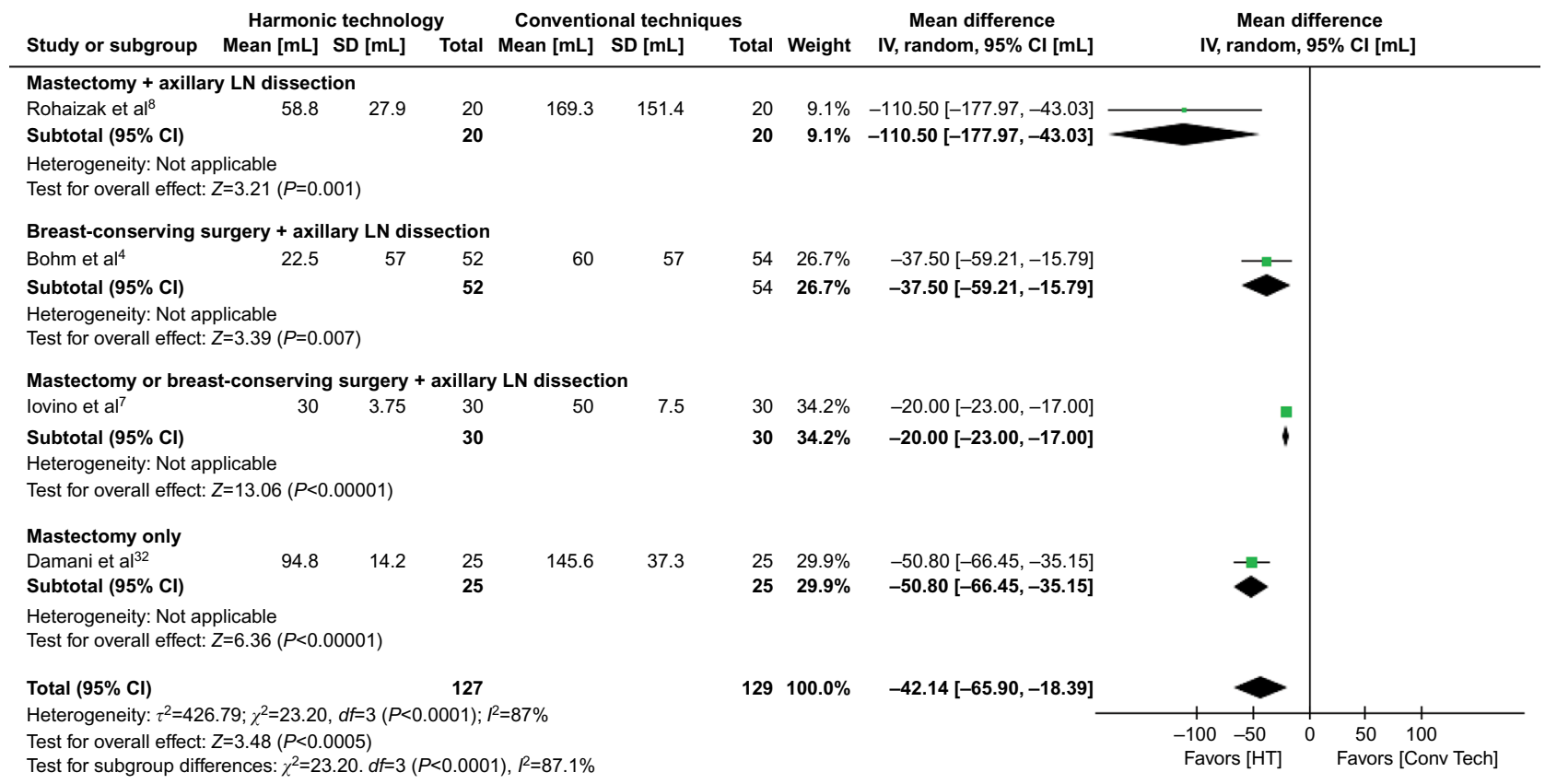

Figure 4 Forest plot of meta-analysis results for postoperative drainage volume $(\mathrm{mL})$ from chest wall.

Abbreviations: SD, standard deviation; Cl, confidence interval; LN, lymph node; HT, Harmonic technology; Conv Tech, conventional techniques; IV, inverse variance.

\section{Overall seroma}

Harmonic technology use was associated with a statistically significant decrease in overall seroma $(\mathrm{RR}=0.54 ; 95 \% \mathrm{CI}$ : 0.43-0.69; $P<0.00001$; eleven studies; $I^{2}=25 \%$ ) (Figure 6; Table 3), a $46 \%$ decrease, compared to conventional methods in breast surgery. All surgical subgroups, with the exception of the single study of mastectomy only (no lymph node dissection), showed a statistically significant reduction in seroma with Harmonic technology.

\section{Hematoma}

Hematoma events were reduced with Harmonic technology use with an RR of 0.57 (95\% CI: 0.30-1.10; $P=0.09$; nine studies; $I^{2}=0 \%$ ) (Table 3 ); however, results demonstrated 


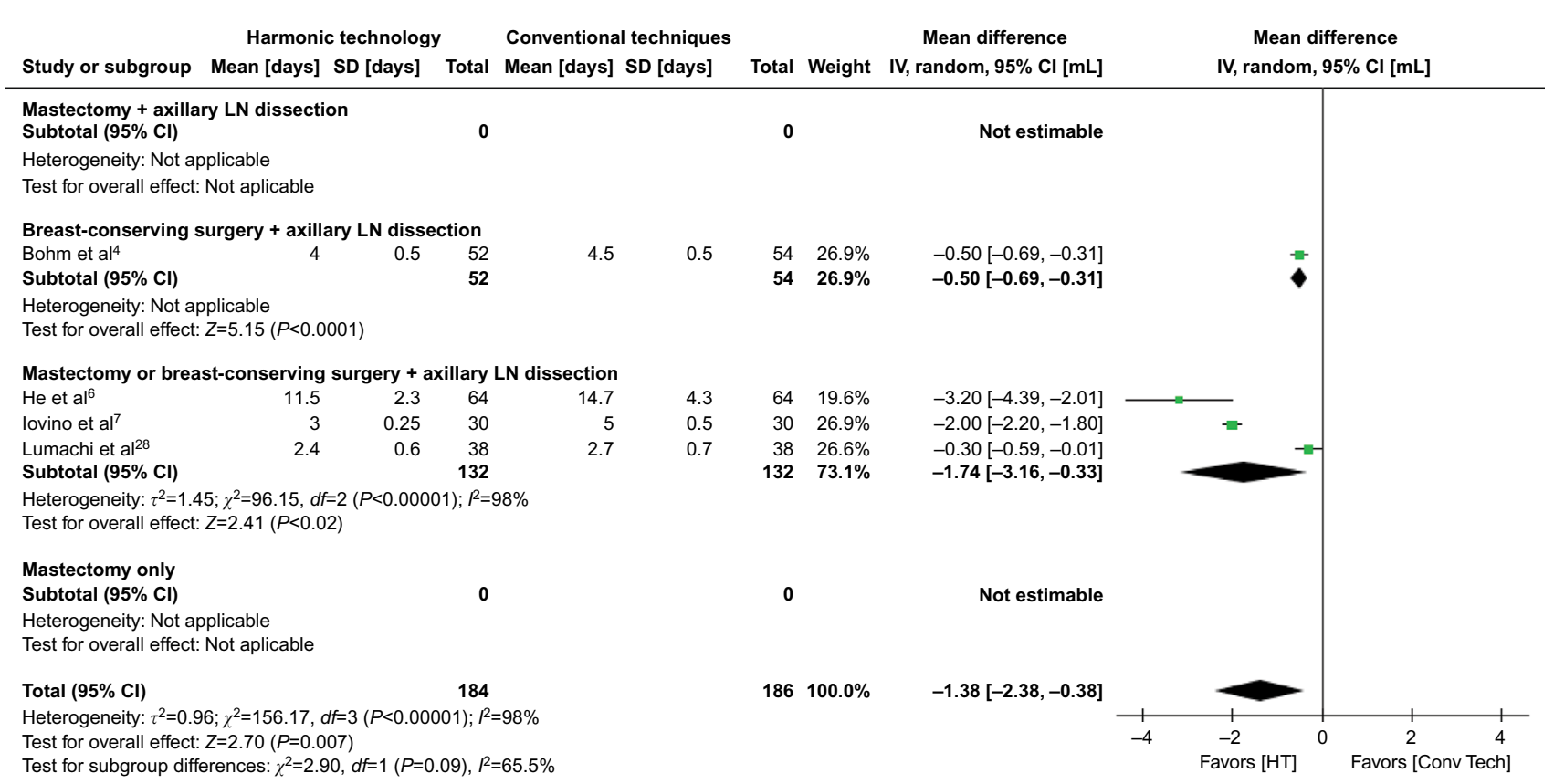

Figure 5 Forest plot of meta-analysis results for postoperative hospital length of stay (days).

Abbreviations: SD, standard deviation; Cl, confidence interval; LN, lymph node; HT, Harmonic technology; Conv Tech, conventional techniques; IV, inverse variance.

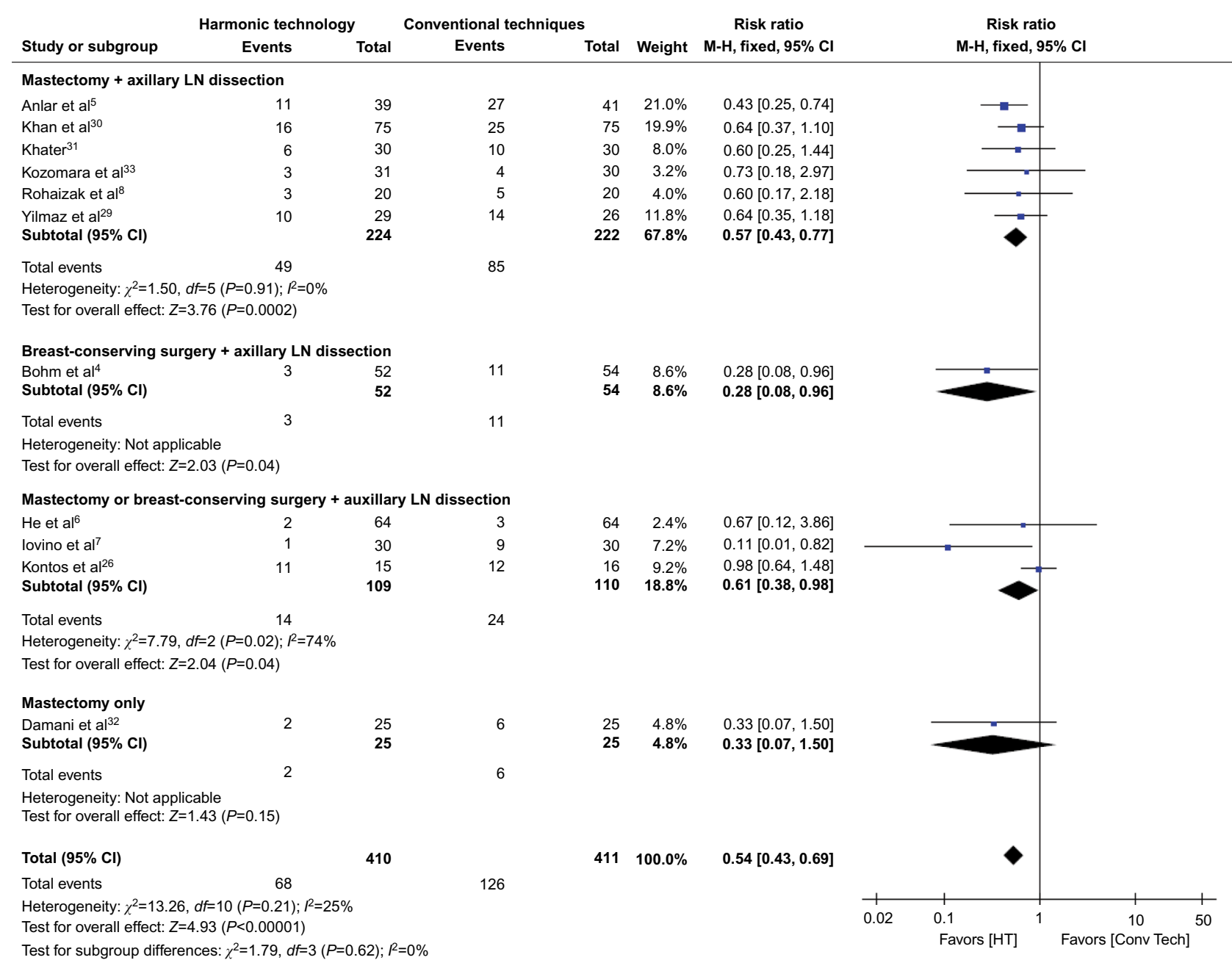

Figure 6 Forest plot of meta-analysis results for overall seroma.

Abbreviations: $\mathrm{Cl}$, confidence interval; LN, lymph node; HT, Harmonic technology; Conv Tech, conventional techniques; IV, inverse variance. 


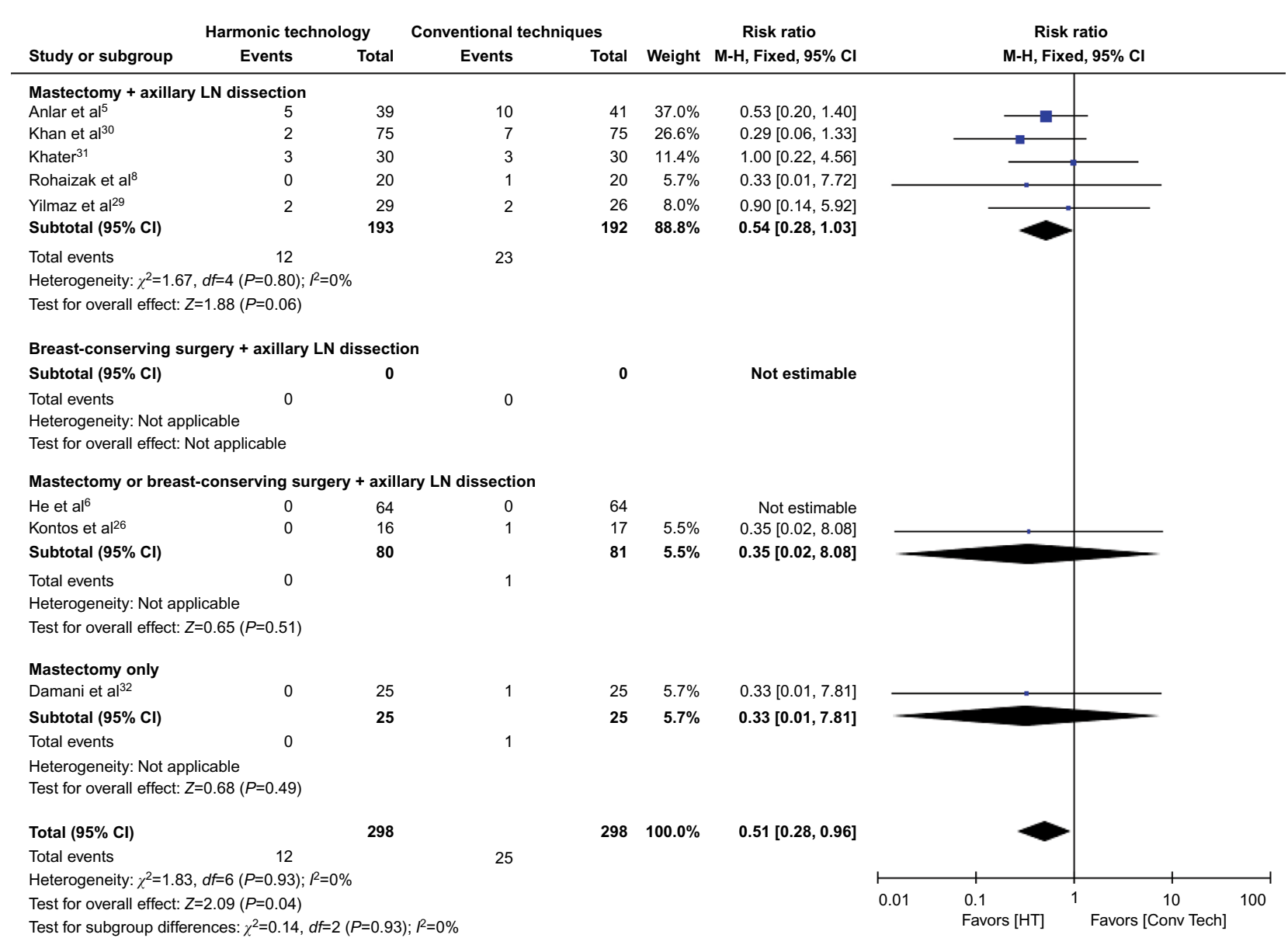

Figure 7 Forest plot of meta-analysis results for necrosis.

Abbreviations: $\mathrm{Cl}$, confidence interval; $\mathrm{LN}$, lymph node; $\mathrm{HT}$, Harmonic technology; Conv Tech, conventional techniques; M-H, Mantel-Haenszel.

no statistically significant difference compared with conventional methods. Most study subgroups showed a nonsignificant reduction in the risk of hematoma with Harmonic technology (low event rates).

\section{Wound infection}

No significant differences were reported between Harmonic technology and conventional methods for the outcome of wound infection in breast surgery $(\mathrm{RR}=0.71 ; 95 \% \mathrm{CI}$ : $0.32-1.56 ; P=0.39$; nine studies; $I^{2}=0 \%$ ) (Table 3 ). Study subgroups showed a nonsignificant reduction in the risk of wound infection with Harmonic technology (low event rates). No data were available for studies of only BCS.

\section{Necrosis}

In contrast to conventional methods in breast surgery, Harmonic technology resulted in a statistically significant reduction in necrosis with an RR of 0.51 (95\% CI: 0.28-0.96; $P=0.04$; eight studies; $P^{2}=0 \%$ ) (Figure 7; Table 3), a $49 \%$ decrease, compared to conventional methods in breast surgery. Study subgroups showed a nonsignificant reduction in the risk of necrosis with Harmonic technology (low event rates). No data were available for studies of only BCS.

\section{Ecchymosis}

Results demonstrated a reduction in ecchymosis events with Harmonic technology compared to conventional techniques (RR $=0.67 ; 95 \% \mathrm{CI}: 0.36-1.25 ; P=0.21$; two studies; $I^{2}=0 \%$ ) (Table 3 ); however, these results were not statistically significant. Results were only available for the mastectomy (with lymph node dissection) subgroup.

\section{Secondary analyses}

In a secondary analysis of dichotomous outcomes reporting on the OR as the effect measure, results remained in favor of Harmonic technology compared with conventional methods in breast surgery. Overall total complications were statistically significantly reduced with Harmonic technology compared with conventional methods with an OR of 0.34 (95\% CI: $0.17-0.66$; two studies; $P=0.002$; $I^{2}=0 \%$ ) (Table $\left.\mathrm{S} 1\right)$. Similarly, overall seroma was significantly reduced with Harmonic technology $(\mathrm{OR}=0.39$; 95\% CI: 
$0.27-0.57$; eleven studies; $P<0.00001 ; I^{2}=0 \%$ ), as was the incidence of necrosis (OR $=0.46$; 95\% CI: 0.23-0.91; eight studies; $P=0.03 ; I^{2}=0 \%$ ) (Table S1).

\section{Sensitivity analyses}

Sensitivity analyses demonstrated results that were similar to the primary analysis and were relatively robust to variables tested (Table 3 ). When excluding studies not randomizing device use in breast surgery, ${ }^{28}$ results minimally changed. Additionally, primary analysis results were relatively robust to the exclusion of studies not randomizing device use in lymph node dissection. ${ }^{5,29}$ However, in this sensitivity analysis, the outcome of hematoma became statistically significant in favor of Harmonic technology, and the outcome of necrosis became nonsignificant but still trended in favor of Harmonic technology. When imputed studies were excluded for operating time, ${ }^{5,7,26}$ this outcome was statistically significantly reduced with Harmonic technology. Results were relatively insensitive to change when imputed studies were excluded for the outcomes of intraoperative blood loss, ${ }^{5,7}$ postoperative drainage volume of the chest wall, ${ }^{4}$ and postoperative hospital length of stay ${ }^{4}$ and remained statistically significant in favor of Harmonic technology. Results for intraoperative blood loss, postoperative drainage volume of the chest wall, postoperative hospital length of stay, and overall seroma remained statistically significantly lower with Harmonic technology when studies of higher risk of bias were excluded (Table 3). Additionally, operating time became statistically significant in favor of Harmonic technology with the exclusion of these "lower" quality studies, while the necrosis outcome remained in favor of Harmonic technology, but the difference was not statistically significant.

\section{Discussion}

Breast cancer surgery, such as modified radical mastectomy, may involve widespread surgical tissue trauma increasing the risk of complications and postoperative morbidity. ${ }^{12}$ Therefore, effective dissection and hemostasis surgical tools are needed to help minimize ensuing risks to the patient. In breast cancer surgeries, our study demonstrated that Harmonic technology significantly reduced the risk of complications, such as intraoperative blood loss, overall seroma, and necrosis compared with conventional methods. In addition, postoperative chest wall drainage and hospital length of stay were both significantly reduced with Harmonic technology compared with conventional methods.

Our study specifically demonstrated that overall risk of complications was reduced by $\sim 50 \%$ with Harmonic technology compared with conventional methods in breast cancer surgery patients. Electrosurgery was a prevalent comparator used in the included studies and is associated with an important risk of surgical morbidity, ranging from $35 \%$ to $50 \%{ }^{12}$ When assessing complication types, the risk of overall seroma (ie, chest, axillary, or both) was significantly reduced by $46 \%$ with Harmonic technology compared with conventional methods. It has been noted that the incidence of seroma can vary widely from $3 \%$ to $85 \%{ }^{34}$ and is more common in mastectomy than BCS procedures. One important cause of seroma is the inadequate sealing of the lymphatics with electrosurgery. It is speculated that Harmonic technology may reduce the risk of seroma with more precise sealing mechanisms and its ability to induce less of an acute inflammatory response relative to electrosurgery. ${ }^{23,29}$ Furthermore, this study demonstrated that the risk of necrosis was also significantly reduced by $\sim 50 \%$ with Harmonic technology. During electrosurgery, direct, high thermal energy is used that can result in the devitalization of tissues. ${ }^{29}$ Harmonic technology reduces the risk of thermal damage, as it operates at lower temperatures, whereby less energy is dispersed to surrounding tissues. ${ }^{19,35}$ For other less common complication types evaluated in this study, including hematoma, wound infection, and ecchymosis, Harmonic technology demonstrated numerical reductions in event rates, although not statistically significant. Given the rarity of some of these events, the possibility of results being underpowered cannot be ruled out. In summary, a reduction in breast cancer surgical complications, as demonstrated with Harmonic technology, may importantly help to prevent delays with adjuvant breast cancer treatments.

Our study can be compared to a recent meta-analysis by Huang et al, ${ }^{23}$ conducted in mastectomy patients with breast cancer. Huang et $\mathrm{al}^{23}$ reported significant reductions in blood loss, seroma, postoperative drainage volume, and wound complications with Harmonic technology, without a change in operating time. However, there are some important differences between this study and the study by Huang et al. ${ }^{23}$ It is reassuring to note that for outcomes compared across both meta-analyses, results are generally similar despite inclusion of different study designs and surgery types. Our study included mastectomy and BCS, whereas Huang et $\mathrm{al}^{23}$ only included mastectomy patients. Furthermore, our study focused on randomized trials only, whereas Huang et $\mathrm{a}^{23}$ included both randomized and nonrandomized comparative studies. When considering the four nonrandomized studies $^{36-39}$ included by Huang et al, ${ }^{23,36-39}$ results often favored Harmonic technology, although were sometimes not statistically significant. For example, the rate of local complications was statistically significantly lower in the Harmonic technology group compared to conventional techniques, 
while complications including seroma, necrosis, hematoma, and infection were not statistically significantly reduced but remained in favor of Harmonic technology.

Subgroup analyses in our study were performed based on the types of surgeries (mastectomy, BCS, or both). Generally, results appeared more favorable for Harmonic technology compared with conventional methods in studies that focused on mastectomy patients. For example, intraoperative blood loss was statistically significantly reduced by Harmonic technology in mastectomy (with lymph node dissection) patients (MD: $-102.91 \mathrm{~mL}, 95 \% \mathrm{CI}:-143.7$ to -62.07 ; $P<0.00001)$ and nonstatistically significantly reduced for Harmonic technology in combined mastectomy and BCS (with lymph node dissection) patients (MD: $-66.62 \mathrm{~mL}, 95 \%$ CI: -159.5 to $26.27 ; P=0.16)$. Similarly, for postoperative chest wall drainage volume, the size of the reduction was greater for Harmonic technology in mastectomy (with lymph node dissection) patients (MD: $-110.5 \mathrm{~mL}$; 95\% CI: -177.97 to $-43.03 ; P=0.001$ ) compared with $\mathrm{BCS}$ (with lymph node dissection) patients (MD: $-37.50 \mathrm{~mL} ; 95 \% \mathrm{CI}:-59.2$ to $-15.79 ; P=0.0007)$. Furthermore, for the outcome of hospital length of stay, Harmonic technology significantly reduced the duration of hospital stay by 1.74 days in studies including both mastectomy and BCS (with lymph node dissection) patients, compared with 0.5 days in studies only reporting on BCS (with lymph node dissection). Overall, although data were limited in exclusive BCS populations, the data that are available in BCS suggest significant benefits with Harmonic technology compared to conventional methods for a reduction in postoperative chest wall drainage volume, hospital length of stay, and overall seroma.

Harmonic technology is more costly upfront than standard techniques (eg, traditional scalpel, sutures, electrosurgery); however, downstream cost savings through averted resource use are essential to consider in total cost calculations. In a recent publication involving thyroidectomy procedures, ${ }^{40} \mathrm{a}$ meta-analysis of seven studies demonstrated that Harmonic technology significantly reduced total hospital costs, considering the reduced operating time and/or length of hospital stay compared with conventional methods. Considering the results of our breast surgery meta-analysis, it may be predicted that the reduction in surgical complications with Harmonic technology may lead to less complication-related treatments and associated costs. Furthermore, our study demonstrated that hospital stay is significantly reduced with Harmonic technology by close to 1.5 days. This reduction in hospital stay is likely attributed to the lower complication risk observed with Harmonic technology in our study, as data demonstrate that postmastectomy complications are associated with prolonged hospital stay. ${ }^{14,32,41,42}$ Given this potential health resource savings, future studies should comprehensively assess the cost-effectiveness of Harmonic technology in breast cancer surgeries.

This study is the most comprehensive meta-analysis to date of RCTs for breast cancer surgeries comparing Harmonic technology to conventional techniques and evaluating a wide range of breast surgery complications. Overall, the randomized trials included in this study were deemed to be of high quality with a fairly low risk of bias. The results of this analysis remained robust to a variety of sensitivity analyses excluding studies that were less methodologically rigorous and using different statistical measures for rare events. Specifically, we used the relative risk measure for all dichotomous outcomes in the primary analysis to enhance interpretability of the study results. In a secondary analysis, all dichotomous outcomes were analyzed using ORs, with the Peto ORs being calculated for outcomes reporting rare events. This method was considered the least biased and most powerful method providing the best CI coverage for rare events. ${ }^{43}$

This study has some limitations. First, high heterogeneity was observed for some continuous outcome measures such as intraoperative blood loss and operating time. This may, in part, be due to the variability in surgeon technique and operating methods used during the surgical procedure and was addressed through the use of a random-effects model. Conversely, statistical heterogeneity was found to be very low for dichotomous, complication-related outcomes. Second, data were not sufficient to be statistically combined in this meta-analysis for the outcome of postoperative pain in the few studies that assessed this outcome given some missing variance measures. In the two studies that reported visual analog scale pain scores, ${ }^{30,33}$ results appeared favorable for Harmonic technology compared with conventional techniques in mastectomy; however, in one study, the $P$-value was not reported. Furthermore, methodological limitations precluded analysis of the outcome of mean number of lymph nodes dissected. Two studies noted a numerically greater number of lymph nodes dissected with Harmonic technology compared with conventional care in breast surgery. ${ }^{6,7}$ Although these two studies could not be statistically pooled, other clinical studies using Harmonic technology support this observation. ${ }^{44} 46$ For example, one study in gastric surgery reported that approximately five more lymph nodes were dissected with Harmonic technology compared with conventional care $(P<0.05) .{ }^{44}$ Harmonic technology is reported to facilitate lymph node dissection based on the generation of an "empty" effect, 
whereby adipose tissue is vaporized and a three-dimensional operation space is created, which facilitates the separation of the lymph nodes and lymphatic tissue from the large blood vessels. ${ }^{47}$ Harmonic technology can thereby coagulate the small lymph node hilar vasculature more easily, resulting in a smooth dissection. ${ }^{47}$ Finally, data were not available to evaluate the important outcome of lymphedema in breast cancer surgery patients. This is due to the limited follow-up time of the included studies, as additional years of data would be required in order to accurately assess this outcome or other sequelae such as cancer recurrence or mortality.

\section{Conclusion}

The current meta-analysis demonstrates that Harmonic technology can significantly reduce the risk of surgical complications, such as overall seroma, blood loss, and necrosis in breast cancer surgery patients compared with conventional methods. Furthermore, Harmonic technology demonstrates significant reductions in postoperative drainage of the chest wall and hospital length of stay, which may be attributed to reduced complications. These demonstrated that reductions in surgical complications with Harmonic technology may ultimately assist in reducing associated downstream health care costs, while offering several clinical advantages in breast cancer surgery.

\section{Acknowledgment}

This study was supported by Ethicon, Inc.

\section{Disclosure}

$\mathrm{HC}$, JWC, and PH are employees of Ethicon Inc., manufacturer of Harmonic devices. NCC, LP, IMS, and CGC are employees of Cornerstone Research Group, Inc., which conducts research on behalf of pharmaceutical and medical devices companies, including Ethicon, Inc.

\section{References}

1. Torre LA, Siegel RL, Ward EM, Jemal A. Global cancer incidence and mortality rates and trends-an update. Cancer Epidemiol Biomarkers Prev. 2016;25(1):16-27.

2. Franceschini G, Martin Sanchez A, Di Leone A, et al. New trends in breast cancer surgery: a therapeutic approach increasingly efficacy and respectful of the patient. G Chir. 2015;36(4):145-152.

3. Veronesi U, Paganelli G, Galimberti V, et al. Sentinel-node biopsy to avoid axillary dissection in breast cancer with clinically negative lymph-nodes. Lancet. 1997;349(9069):1864-1867.

4. Bohm D, Kubitza A, Lebrecht A, et al. Prospective randomized comparison of conventional instruments and the Harmonic Focus $((\mathrm{R}))$ device in breast-conserving therapy for primary breast cancer. Eur J Surg Oncol. 2012;38(2):118-124.

5. Anlar B, Karaman N, Dogan L, Ozaslan C, Atalay C, Altinok M. The effect of harmonic scalpel, electrocautery, and scalpel use on early wound complications after modified radical mastectomy. Eur Surg. 2013;45(6):286-290.
6. He Q, Zhuang D, Zheng L, et al. Harmonic focus versus electrocautery in axillary lymph node dissection for breast cancer: a randomized clinical study. Clin Breast Cancer. 2012;12(6):454-458.

7. Iovino F, Auriemma PP, Ferraraccio F, Antoniol G, Barbarisi A. Preventing seroma formation after axillary dissection for breast cancer: a randomized clinical trial. Am J Surg. 2012;203(6):708-714.

8. Rohaizak M, Khan FJ, Jasmin JS, Mohd Latar NH, Abdullah SS. Ultracision versus electrocautery in performing modified radical mastectomy and axillary lymph node dissection for breast cancer: a prospective randomized control trial. Med J Malaysia. 2013;68(3):204-207.

9. Miller E, Paull DE, Morrissey K, Cortese A, Nowak E. Scalpel versus electrocautery in modified radical mastectomy. Am Surg. 1988;54(5):284-286.

10. Banerjee D, Williams EV, Ilott J, Monypenny IJ, Webster DJ. Obesity predisposes to increased drainage following axillary node clearance: a prospective audit. Ann R Coll Surg Engl. 2001;83(4):268-271.

11. Morrow M, Jagsi R, Alderman AK, et al. Surgeon recommendations and receipt of mastectomy for treatment of breast cancer. JAMA. 2009;302(14):1551-1556.

12. Vinton AL, Traverso LW, Jolly PC. Wound complications after modified radical mastectomy compared with tylectomy with axillary lymph node dissection. Am J Surg. 1991;161(5):584-588.

13. W.H.E.C. Gynecologic Oncology: Breast Cancer Surgical Treatment Complications \& Lymphedema. Vol. 2016. Springfield, MA: WHEC; 2011.

14. Woodworth PA, McBoyle MF, Helmer SD, Beamer RL. Seroma formation after breast cancer surgery: incidence and predicting factors. $\mathrm{Am}$ Surg. 2000;66(5):444-450. discussion 450-441.

15. Sheen-Chen SM, Chou FF. A comparison between scalpel and electrocautery in modified radical mastectomy. Eur J Surg. 1993;159(9):457-459.

16. Porter KA, O’Connor S, Rimm E, Lopez M. Electrocautery as a factor in seroma formation following mastectomy. Am J Surg. 1998;176(1): $8-11$.

17. Deo SV, Shukla NK. Modified radical mastectomy using harmonic scalpel. J Surg Oncol. 2000;74(3):204-207.

18. Carlander J, Johansson K, Lindström S, Velin AK, Jiang CH, Nordborg C. Comparison of experimental nerve injury caused by ultrasonically activated scalpel and electrosurgery. Br J Surg. 2005;92(6): 772-777.

19. Bandi G, Wen CC, Wilkinson EA, Hedican SP, Moon TD, Nakada SY. Comparison of blade temperature dynamics after activation of Harmonic Ace scalpel and the Ultracision Harmonic Scalpel LCS-K5. J Endourol. 2008;22(2):333-336.

20. Zhang ZJ, Zhang P, Tian JH, et al. Ultrasonic coagulator for thyroidectomy: a systematic review of randomized controlled trials. Surg Innov. 2010;17(1):41-47.

21. Cheng H, Hsiao CW, Clymer JW, et al. Gastrectomy and D2 lymphadenectomy for gastric cancer: a meta-analysis comparing the harmonic scalpel to conventional techniques. Int J Surg Oncol. 2015;2015:397260.

22. Cheng H, Soleas I, Ferko NC, Clymer JW, Amaral JF. A systematic review and meta-analysis of Harmonic Focus in thyroidectomy compared to conventional techniques. Thyroid Res. 2015;8:15.

23. Huang J, Yu Y, Wei C, Qin Q, Mo Q, Yang W. Harmonic Scalpel versus electrocautery dissection in modified radical mastectomy for breast cancer: a meta-analysis. PLoS One. 2015;10(11):e0142271.

24. Deeks J, Higgins J, Altman D, Green S. Cochrane handbook for systematic reviews of interventions version 5.1.0 (updated March 2011). The Cochrane Collaboration. 2011.

25. Hozo SP, Djulbegovic B, Hozo I. Estimating the mean and variance from the median, range, and the size of a sample. BMC Med Res Methodol. 2005;5:13.

26. Kontos M, Kothari A, Hamed H. Effect of harmonic scalpel on seroma formation following surgery for breast cancer: a prospective randomized study. J BUON. 2008;13:223-230.

27. Sweeting MJ, Sutton AJ, Lambert PC. What to add to nothing? Use and avoidance of continuity corrections in meta-analysis of sparse data. Stat Med. 2004;23(9):1351-1375. 
28. Lumachi F, Burelli P, Basso SM, Iacobone M, Ermani M. Usefulness of ultrasound scissors in reducing serous drainage after axillary dissection for breast cancer: a prospective randomized clinical study. Am Surg. 2004;70(1):80-84.

29. Yilmaz KB, Dogan L, Nalbant H, et al. Comparing scalpel, electrocautery and ultrasonic dissector effects: the impact on wound complications and pro-inflammatory cytokine levels in wound fluid from mastectomy patients. J Breast Cancer. 2011;14(1):58-63.

30. Khan S, Khan S, Chawla T, Murtaza G. Harmonic scalpel versus electrocautery dissection in modified radical mastectomy: a randomized controlled trial. Ann Surg Oncol. 2014;21(3):808-814.

31. Khater A. Harmonic scalpel as a single instrument in modified radical mastectomy. Is it more cost effective than electrocautery and ligature? Egypt J Surg. 2010;29:59-63.

32. Damani SR, Haider S, Shah SSH. Comparison of modified radical mastectomy using harmonic scalpel and electrocautery. JSurg Pak. 2013;18:1-5.

33. Kozomara D, Galić G, Brekalo Z, Sutalo N, Kvesić A, Soljić M. A randomised two-way comparison of mastectomy performed using harmonic scalpel or monopolar diathermy. Coll Antropol. 2010;34(suppl 1):105-112.

34. Kumar S, Lal B, Misra MC. Post-mastectomy seroma: a new look into the aetiology of an old problem. J R Coll Surg Edinb. 1995;40(5):292-294.

35. Ecker T, Carvalho AL, Choe JH, Walosek G, Preuss KJ. Hemostasis in thyroid surgery: harmonic scalpel versus other techniques - a metaanalysis. Otolaryngol Head Neck Surg. 2010;143(1):17-25.

36. Adwani A, Ebbs SR. Ultracision reduces acute blood loss but not seroma formation after mastectomy and axillary dissection: a pilot study. Int $J$ Clin Pract. 2006;60(5):562-564.

37. Ribeiro GH, Kerr LM, Haikel RL, et al. Modified radical mastectomy: a pilot clinical trial comparing the use of conventional electric scalpel and harmonic scalpel. Int J Surg. 2013;11(6):496-500.
38. Galatius H, Okholm M, Hoffmann J. Mastectomy using ultrasonic dissection: effect on seroma formation. Breast. 2003;12(5):338-341.

39. Deo SV, Shukla NK, Asthana S, Niranjan B, Srinivas G. A comparative study of modified radical mastectomy using harmonic scalpel and electrocautery. Singapore Med J. 2002;43(5):226-228.

40. Cheng H, Soleas IM, Ferko NC, et al. Hospital costs associated with thyroidectomy performed with a harmonic device compared to conventional techniqes: a systematic review and meta-analysis. J Med Econ. 2016. (Epub 2016 Apr 5).

41. Tejler G, Aspegren K. Complications and hospital stay after surgery for breast cancer: a prospective study of 385 patients. Br J Surg. 1985; 72(7):542-544.

42. Lumachi F, Brandes AA, Burelli P, Basso SM, Iacobone M, Ermani M. Seroma prevention following axillary dissection in patients with breast cancer by using ultrasound scissors: a prospective clinical study. Eur J Surg Oncol. 2004;30(5):526-530.

43. Lane PW. Meta-analysis of incidence of rare events. Stat Methods Med Res. 2013;22(2):117-132.

44. Huang Y, Mu GC, Qin XG, et al. The application of ultrasonic harmonic scalpel in the radical surgery of gastric cancer. Clin Transl Oncol. 2013; 15(11):932-937.

45. Huang Y, Mu GC, Qin XG, Chen ZB, Lin JL, Zeng YJ. Study of celiac artery variations and related surgical techniques in gastric cancer. World J Gastroenterol. 2015;21(22):6944-6951.

46. Hung SH, Chu D, Chen FM, Chen T, Chen RC. Evaluation of the harmonic scalpel in breast conserving and axillary staging surgery. $J$ Chin Med Assoc. 2012;75(10):519-523.

47. Salvia R, Malleo G, Marchegiani G, Butturini G, Esposito A, Bassi C. Pancreaticoduodenectomy with harmonic focust curved shears for cancer. Dig Surg. 2014;31(4-5):249-254. 


\section{Supplementary materials}

\section{Literature search strategy}

The following search strategy was used in MEDLINE, where

"MeSH" indicates Medical subject headings:

1. "harmonic scalpel" OR ultracision OR "ultrasonic scalpel" OR "ultrasonically activated scalpel" OR "ultrasound scalpel" OR "harmonic shears" OR "ultrasonic shears" OR "ultrasonic scissors" OR "laparosonic" OR "coagulating shears" OR "ultrasound shears" OR "ultrasonically activated shears" OR "harmonic blade" OR "ultrasonic blade" OR "harmonic hook" OR "ultrasonic hook" OR "Harmonic Focus" OR "Harmonic ACE" OR "Harmonic Wave" OR "Harmonic Synergy" [Title/Abstract]

2. "Comparative Study" OR "Controlled Clinical Trial" OR "Randomized Controlled Trial" [Publication Type]

3. Humans $[\mathrm{MeSH}]$

4. \#1 AND \#2 AND \#3

Table SI Secondary analysis of dichotomous outcomes using the OR, Mantel-Haenszel method with a fixed-effects model

\begin{tabular}{lll}
\hline Outcome & $\begin{array}{l}\text { Secondary analysis (OR [95\% Cl]; } \\
I^{\mathbf{2}} \text { value) }\end{array}$ & P-value \\
\hline Total complications & $0.34[0.17-0.66] ; 0 \%$ & $\mathbf{0 . 0 0 2}$ \\
Overall seroma & $0.39[0.27-0.57] ; 0 \%$ & $<\mathbf{0 . 0 0 0 0 ~ I ~}$ \\
Hematoma & $0.53[0.26-1.08] ; 16 \%$ & 0.08 \\
Wound infection & $0.67[0.29-1.58] ; 0 \%$ & 0.37 \\
Necrosis & $0.46[0.23-0.91] ; 0 \%$ & $\mathbf{0 . 0 3}$ \\
Ecchymosis & $0.60[0.27-1.34] ; 0 \%$ & 0.21 \\
\hline
\end{tabular}

Notes: The analysis of outcomes with rare events (event rate $<1 \%$ ) was conducted using Peto OR. A P-value less than 0.05 (in bold) is considered statistically significant.

Abbreviations: $\mathrm{OR}$, odds ratio; $\mathrm{Cl}$, confidence interval.

\section{Publish your work in this journal}

Breast Cancer - Targets and Therapy is an international, peerreviewed open access journal focusing on breast cancer research, identification of therapeutic targets and the optimal use of preventative and integrated treatment interventions to achieve improved outcomes, enhanced survival and quality of life for the cancer patient.

The manuscript management system is completely online and includes a very quick and fair peer-review system, which is all easy to use. Visit $\mathrm{http}: / / \mathrm{www}$.dovepress.com/testimonials.php to read real quotes from published authors. 